\title{
Intervenção compartilhada em uma sala de aula inclusiva: uma experiência metodológica no ensino de História
}

\author{
Roseli Inês Hickmann* \\ Maria Isabel Dalla Zen** \\ Maria Luísa Merino de Freitas Xavier***
}

\section{Resumo}

O presente estudo buscou analisar uma experiência metodológica no ensino de História, a partir do processo de intervenção compartilhada numa sala de aula inclusiva, desenvolvida numa Escola Municipal de Porto Alegre, RS, organizada por Ciclos de Formaçáo, na qual a turma do $1^{\circ}$ ano do $3^{\circ}$ ciclo investigada integrou o Projeto Docência Compartilhada. Tal projeto foi desenvolvido contemplando o planejamento didático-pedagógico e a docência em sala de aula de forma conjunta por duas professoras - uma professora licenciada em História e outra em Pedagogia. Entre os desdobramentos significativos deste estudo, apontou-se a intervenção compartilhada como uma experiência metodológica para o ensino de História. Desta experiência decorreram: um inventário com os registros escritos pelas professoraspesquisadoras e a leitura dos mesmos pelas professoras-regentes; as reunióes de discussão dos escritos e dos encaminhamentos. Percebeu-se que a partir da intervenção compartilhada, como uma experiência metodológica no ensino de História, os alunos com necessidades educativas especiais apresentaram um tempo e um modo peculiar de se apropriarem dos conhecimentos, assim como os demais alunos sentiram-se interpelados por esse modo singular de aprender. Também se constatou que as professoras-regentes transmutaram-se em protagonistas de práticas pedagógicas ressignificadas, enquanto as professoras-pesquisadoras tornaram-se aprendizes de uma postura investigativa denominada, nesse contexto, de intervenção compartilhada.

Palavras-chave: Inclusão. Aprendizagem. Ensino de História.

* Doutora em Educação pela Universidade Federal do Rio Grande do Sul (UFRGS). Professora do Departamento de Ensino e Currículo da Faculdade de Educação da Universidade Federal do Rio Grande do Sul(UFRGS).

** Doutora em Educação pela Universidade Federal do Rio Grande do Sul (UFRGS). Professora do Departamento de Ensino e Currículo da Faculdade de Educação da Universidade Federal do Rio Grande do Sul. (UFRGS).

*** Doutora em Educação pela Universidade Federal do Rio Grande do Sul (UFRGS). Professora convidada da Faculdade de Educação da Universidade Federal do Rio Grande do Sul (UFGRS). 


\section{Introdução}

O presente texto tem como propósito socializar e analisar uma experiência metodológica no ensino de História por meio da intervenção compartilhada, em uma sala de aula inclusiva de uma Escola Municipal de Porto Alegre/RS, organizada por ciclos de formação (constituída por três ciclos de três anos cada, totalizando nove anos de Ensino Fundamental).

A turma pesquisada faz parte do Projeto de Docência Compartilhada (DC) da referida escola e é denominada de $\mathrm{C} 12$, compreendendo vinte e cinco alunos/as, sendo sete considerados/as com necessidades especiais. Tal turma corresponde ao $1^{\circ}$ ano do $3^{\circ}$ ciclo do Ensino Fundamental e abrange alunos/as de 12 a 15 anos.

Cabe esclarecer que a Docência Compartilhada refere-se ao projeto que inicialmente foi implementado em quatro escolas da Rede Municipal de Ensino de Porto Alegre, a partir de 2008, visando inserir alunos das turmas de progressão em turmas regulares, considerando a organização curricular por ciclos de formação. Tal projeto foi organizado para ser planejado e desenvolvido nas salas de aula, de forma conjunta, por duas professoras - neste caso uma Pedagoga e uma licenciada em História - com intençốes de oportunizar aprendizagens diferenciadas, a partir da inclusão no mesmo espaço pedagógico de alunos ditos "normais" e alunos com necessidades especiais, que apresentam ritmos singulares e diversificados em termos de apropriação e de ressignificação dos saberes escolarizados.

No ano de 2011, como integrantes de um grupo de pesquisa ${ }^{1}$ de uma universidade pública do sul do país, nos aproximamos das professoras Alice e Rosana ${ }^{2}$, tendo como foco, inicialmente, o ensino e as aprendizagens "na C12", tendo em vista a peculiaridade da DC e o fato de sete alunos desta turma apresentarem necessidades educativas especiais ${ }^{3}$ em várias dimensões (Transtorno Global do Desenvolvimento autismo -, deficiência mental etc.), o que veio ao encontro do tema central de estudo do nosso grupo de pesquisa: os processos educacionais inclusivos. Situamos, aqui, a atividade de observação como meta inicial, porque, paulatinamente, ela teve desdobramentos significativos, conforme aponta o título deste estudo.

Manguel (2006) nos diz que frente a essa leitura clara, diurna, podemos construir uma outra forma de ler: noturna e com limites e certezas não tão definidos. Compactuamos com o autor e seguimos na busca de outra leitura da sala de aula das professoras Alice e Rosana. Enveredamos, entáo, por uma leitura pautada pela humildade intelectual; pela leitura da expectativa, da curiosidade, da observação inquieta e cuidadosa. A vida da sala de aula - assim como os textos escritos que por ela circulam - pode ser lida de várias maneiras: sensível, atenciosa e amavelmente (ou 
não...). Há uma pluralidade de formas de ser e estar ali; também, uma variedade de modos de aprender, de conviver em grupo, de planejar, ensinar e avaliar em dupla, como neste caso da DC: cooperando, trocando, revendo e refazendo práticas pedagógicas. Assim sendo, experimentamos a leitura noturna e com limites e certezas não tão definidos, tal como aponta Manguel (2006), pois esta visão em relação à sala de aula é que nos permitiu/permite "ler" as diferentes formas de aprendizagens.

Para tanto, recorremos à etnografia que conforme Sarmento (2003, p.153),

[...] visa apreender a vida, tal qual ela é quotidianamente conduzida, simbolizada e interpretada pelos actores sociais nos seus contextos de acção. Ora, a vida é, por definição, plural nas suas manifestaçóes, imprevisível no seu desenvolvimento, expressa não apenas nas palavras, mas também nas linguagens dos gestos e das formas, ambígua nos seus significados e múltipla nas direcçóes e sentidos por que se desdobra e percorre.

Os alunos "da C12", bem como Alice e Rosana tornaram-se, dessa maneira, os nossos "livros-jovens", abertos, coloridos, brincantes, perguntadores, silenciosos, para que buscássemos significações sobre as atividades planejadas e as inusitadas aprendizagens, desejando, dessa forma, compreender a vida plural que pulsava nesta sala de aula inclusiva. Por isso, justifica-se a utilização da palavra-conceito experiência. Neste texto, a empregamos no sentido descrito por Bondía (2002): a experiência como algo que nos passa e que nos toca profundamente, potencializando nossas açóes.

Neste sentido de experiência, o que nos chamou a atenção é que, apesar de nos sentirmos familiarizadas e pertencendo ao contexto escolar, ou seja, "nativas", nos dizeres de Sarmento (2003), esta investigaçáo nos interpelou como uma experiência, um acontecimento no qual estivemos expostas ao inusitado da sala de aula. Como nos lembra Bondía (2004, p. 161):

O sujeito da experiência é um sujeito ex-posto. Do ponto de vista da experiência, o importante não é nem a posição (nossa maneira de pôr-nos), nem a o-posição (nossa maneira de opornos), nem a im-posição (nossa maneira de impor-nos), nem a pro-posição (nossa maneira de propor-nos), mas a exposição, nossa maneira de ex-por-nos, com tudo o que isso tem de vulnerabilidade e de risco. Por isso é incapaz de experiência aquele que se póe, ou se opóe, ou se impóe, ou se propóe, mas não se ex-póe. É incapaz de experiência aquele a quem nada lhe passa, a quem nada lhe toca, nada lhe chega, nada lhe afeta, a quem nada lhe ameaça, a quem nada lhe fere. 
Igualmente, julgamos importante delinear nossa compreensão a respeito do conceito de diferença, uma vez que estamos interessadas em investigar, como já dito, processos educacionais inclusivos. Também pelo fato de termos mencionado as chamadas necessidades educativas especiais, admitindo, assim, que alguns alunos "da C12" - bem como de várias turmas da escola em questáo - apresentam tais necessidades de modo mais acentuado. Em nossa concepção, portanto, essas necessidades são reconhecidas como diferenças. Sobre a noção de diferença, vejamos as palavras provocadoras de Gallo (2009, p. 7):

A noção de diferença ganhou o mundo, no final do século vinte. E chegou ao campo teórico da educaçáo e às escolas. Educar a diferença; educar na diferença; educar para a diferença passaram a ser as palavras de ordem em planos de educaçáo de órgãos governamentais, em projetos políticos pedagógicos de escolas, em projetos de organizaçóes não governamentais. Projetos multiculturais proliferam, culturas de paz, tolerância e convivência consensual são afirmadas nos mais diversos âmbitos. Afirmamos o multiculturalismo e o respeito à diversidade e dormimos em paz com nossa consciência burguesa.

As palavras do autor suscitam alguns posicionamentos sobre como, no decorrer de nossas investigaçóes, estamos lidando com a complexidade deste conceito nas práticas de pesquisa. Ele nos diz que "a diferença está aí, sempre esteve, para quem teve olhos para ver... E não está para ser reconhecida, respeitada, tolerada. Tudo isso implica tentar apagar a diferença, não vê-la e vivê-la" (GALLO, 2009, p. 7). Para experimentar a diferença, contínua, é preciso mudar os "óculos filosóficos". Tomar a diferença em si mesma e para si mesma, sem ser relativa a algo. Significa deslocar o referencial da unidade para a multiplicidade (inclusive a multiplicidade de semelhanças que existem entre jovens e crianças em uma sala de aula). Diferenças que não podem ser reduzidas ao uno/fixo, diferenças que não estão para serem toleradas, aceitas, normalizadas. Diferenças pelas diferenças, numa política do diverso (GALLO, 2009).

Cabe lembrar que, ao nos posicionarmos como suscetíveis aos deslocamentos que a experiência pode produzir, percebemos que esta nos direcionou para a afirmação das diferenças, no sentido de reinventar posturas e maneiras de nos relacionar com o outro para além da tolerância. Tal processo de reinvençấo nos interrogou constantemente sobre possíveis atitudes de apenas aceitar, "tolerar" a diferença do outro, sem o necessário distanciamento de uma relação de poder assimétrica instaurada entre os sujeitos. Por esse motivo, buscamos relacionar o exercício das diferenças - 
também nas discussōes com as professoras - com a possibilidade de recriar práticas de convivência em que estivessem presentes relaçóes de alteridade. Ainda de acordo com o pensamento de Gallo (2006, p. 2),

[...] a alteridade está aí, é uma das constituidoras da diferença e o que podemos tentar construir, em educação, são práticas de convívio no dissenso, na diferença, em meio aos outros. Qualquer forma de "respeito" ao outro desliza para uma espécie de "tolerância", que nada tem de vivência na e da diferença.

Ou seja, ao acolher os denominados diferentes no contexto escolar é importante atentar para a diversidade de subjetividades que constituem a diferença, com o intuito de se conviver pedagogicamente com essa permanente tensão de sermos diversamente diferentes.

Assim, uma das questôes com a qual nos deparamos e que permeou/permeia nossos estudos poderia ser assim resumida: é esta forma de encarar as diferenças uma pretensão possível? Para nós, é um desafio desejável; na escola em que atuamos como pesquisadoras também visualizamos este entendimento, mas não sem tensôes, incertezas, discussóes e revisôes constantes. Essas revisôes constantes, assim caracterizadas, nos direcionam para viver as "consequências" da experiência.

\section{Nossa "experiência" na sala de aula...}

Os alunos costumavam trabalhar em grupos e assim sempre estavam dispostos. A sala de aula contava com materiais didáticos de uso coletivo (mural, canetas coloridas, lápis de cor, régua, folhas, cartolina, entre outros). Uma sala acolhedora! Produçôes do grupo geralmente expostas nas paredes e renovadas conforme o tema curricular em pauta. As professoras Alice e Rosana tinham o hábito de circular entre os grupos após a explicação da tarefa. Quando começamos nosso período de observaçóes ${ }^{4}-$ de abril a junho de 2011 - a turma estava estudando a Mesopotâmia. Rosana (a professora de História) pediu que um aluno esclarecesse o trabalho que estavam realizando. Demonstraram certo constrangimento em interagir com as visitantes (recémchegadas), mas um menino nos informou que fariam, naquele dia, um cartaz sobre o assunto, a partir das pesquisas já realizadas.

Sentamo-nos mais ao fundo da sala e, em seguida, levantamos, sem combinar, para conversar com os alunos em seus grupos de trabalho. Neste primeiro contato, fomos identificando náo somente a aluna P. (diagnosticada com a síndrome do espectro autista), como também outros alunos com necessidades educativas especiais bem acentuadas (entre os demais alunos "ditos normais", com toda sua efervescência 
juvenil). Seus corpos, suas expressóes fisionômicas e linguísticas, bem como nossa interlocução com esses alunos sinalizaram tal condição. De modo geral, foram solícitos e cordiais conosco. Responderam às perguntas que fizemos, teceram comentários sobre como dividiriam as tarefas no grupo de trabalho ("não gosto de desenhar", "eu é que vou escrever", "o E. vai pintar"). Foram abrindo-se em páginas...

Aos poucos foram diminuindo as aparentes resistências e aceitando dialogar com as observadoras participantes. Sugerimos que uma menina ajudasse a colega, segurando a régua, enquanto esta fazia, com dificuldade, o traçado das linhas. Neste grupo, a escrita do texto foi dividida entre dois integrantes. Já percebemos, neste momento, o corpo irrequieto da menina C.: poucas palavras conosco, olhar meio evasivo, como de alguém que ainda não sabe bem (desconfia sobre...) o que estamos fazendo ali. Através de conversas com as professoras regentes, ficamos sabendo que o histórico desta aluna pode ser considerado de vulnerabilidade social. O termo vulnerabilidade social é entendido, neste contexto, como o resultado negativo da relação entre disponibilidade dos recursos materiais ou simbólicos dos sujeitos, sejam indivíduos ou grupos, e o acesso à estrutura de oportunidades sociais, econômicas, culturais que provém do Estado, do mercado e da sociedade. Esse resultado se traduz em debilidade ou desvantagens para o desempenho e mobilidade social dos sujeitos (ABRAMOVAY, 2002).

Em outro grupo, quando surgiu o problema de espaço restrito disponível no papel, tendo em vista que escreveram com letras grandes (de acordo com um cartaz legível, diga-se de passagem), pediram ajuda à Rosana. Neste ínterim, sugerimos que aproveitassem o espaço restante da cartolina para representar a terra entre rios (eles tinham o excerto relativo ao significado da palavra Mesopotâmia). Gostaram da ideia: professora Rosana e alunos! Logo o grupo decidiu que E. (um menino com defasagem cognitiva) iria pintar o desenho dos rios. Estimulamos para que ele fizesse um rascunho. Presenciamos uma alegria enorme na execução da tarefa pelo menino. Assim, fomos percorrendo os grupos de trabalho (pesquisadoras-professoras), tentando uma opiniáo aqui e ali, incluindo comentários, perguntas sobre o que estavam desenhando, sobre significados de palavras. Enquanto isso ocorria, as professoras regentes atendiam outros grupos, fazendo suas intervençôes. Foi uma aula com "quatro professoras". Esse formato repetiu-se de abril a junho, nos dois primeiros períodos das terças-feiras, na aula de História.

Esse cenário faz pensar nas salas de aula lotadas de alunos, com apenas uma professora a "dar conta" das diferenças nas mais variadas dimensôes.

Antes de finalizarem o trabalho, perguntamos qual seria o destino da produção. Rosana informou que faria a exposição dos cartazes. Sugerimos que antes os alunos 
pudessem apresentar o que fizeram. Sob nossa ótica, esse evento comunicativo (gênero discursivo apresentaçáo de trabalho) faz organizar o pensamento, o argumento, a informaçáa, além de valorizar a produçáo, dar sentido ao feito. $\mathrm{O}$ cartaz enquanto gênero textual, afinal, náo tem a função de comunicar algo a algum destinatário? E assim aconteceu. Iniciou-se, então, o que estamos nomeando de intervenção compartilhada em uma sala de aula inclusiva como uma possível estratégia/experiência metodológica no ensino de História. Ao interagirmos constantemente com os alunos e as professoras, por meio de interlocuçóes durante e após os trabalhos em sala de aula, estávamos deslocando lugares que tradicionalmente são atribuídos aos sujeitos que pesquisam e aos que são pesquisados e, dessa forma, ressignificando experiências de aprendizagens, tanto dos saberes escolares quanto de posturas metodológicas.

Nesse sentido, nossa visão de intervenção compartilhada aproxima-se, em alguma medida, do conceito de pesquisa participante em virtude da implicação das pesquisadoras nas atividades de sala de aula, tanto no planejamento quanto na análise e implementação do mesmo. Distancia-se de tal conceito ao conceber esta participação de forma rizomática (KENSKI, 1998), isto é, considerando os conhecimentos em suas ramificaçóes, multiplicidades e heterogeneidades, bem como destituídos de relaçóes de poder hierarquizadas, deslocando-se, portanto, das dicotomias, binarismos e essencialidades.

Na preparação da apresentação oral, chamou-nos a atenção o fato de alguns alunos estarem auxiliando colegas no conteúdo a ser exposto por eles: foi o caso do E., que informaria que Mesopotâmia significa terra entre rios (ele pronunciou a palavra terra, mostrando a representaçáo e depois apontou os rios). A menina I. ${ }^{5}$ (aluna muito participativa) ensaiou, várias vezes, com E. sua apresentaçáo. Outro fato importante, sob nosso olhar, foi a atitude da aluna P. (portadora da síndrome do espectro autista) durante o trabalho: ela se manteve, durante os dois períodos, sentada, envolvida parcialmente - ou "do seu jeito peculiar" (sentada meio de lado, segurando a cabeça com a mão, "espiando", vez ou outra, as "visitantes") - com os acontecimentos da sala de aula; pintou parte do cartaz e concordou em ir à frente da sala apresentar a produção com seu grupo. Eventualmente, dirigia-se aos colegas mais próximos empurrando-os, tocando-os com força, como se estivesse "puxando uma conversa" e, ao mesmo tempo, dando vazão às necessidades de movimento do seu corpo. P. pinta com força (prensa!). Fica longo tempo em um mesmo espaço do papel (uma colega percebe e movimenta sua mão). Neste dia ela não interagiu verbalmente conosco a não ser pelo olhar. Tais atitudes nos fizeram pensar nos indícios de aprendizagens da aluna P.: estar ali, interagir com seus pares, participar das atividades em sala de aula são elementos importantes do seu processo de socialização/escolarização, bem como permitem, também, o exercício da diferença para o coletivo da turma. 
Alice e Rosana, reiteramos, circulavam o tempo todo na sala, auxiliando os alunos na execução das tarefas. Alice mostrou-nos o caderno da P., bem como alguns investimentos no sentido de adaptaçáo de algumas atividades para a menina como, por exemplo, a escrita de texto pela professora (professora escriba), a partir das ideias verbalizadas oralmente pela aluna. Alice tem trabalhado com recortes de revistas, mostrando objetos, enquanto a aluna nomeia-os (estudo dos substantivos e seus atributos). A professora relatou-nos que P. tem conhecimentos sobre letras e números (montou seu nome espelhado com letras móveis e foi surpreendida pelos colegas contando números em voz alta). A turma silenciou para ouvi-la nesta ocasião, destacando o fato como surpreendente. Também ficamos sabendo que ela interage bem com a K. (uma aluna monitora também com necessidades educativas especiais) na situação que as professoras chamam de triangulação: duas pessoas falam sobre P. (professora e monitora) e ela sente-se interpelada, engajando-se na interação. Tentativas, experimentaçóes pedagógicas para "fazer falar, fazer aprender".

Este aprendizado de olhar pesquisador das professoras regentes, que se "o-póem, se ex-póem e pro-póem” (BONDÍA, 2004, p. 161) envolve açốes reflexivas e detalhadas do pensar, uma ação altamente movimentada para "buscar o outro". As aulas eram/são planejadas para todos e algumas adaptaçôes/diferenciaçóes de propostas e materiais didáticos - redução da extensão de alguns textos informativos, ou divisão desses textos em partes para uma leitura em etapas, elaboração de listas de palavras significativas após a leitura, por exemplo, são feitas com o objetivo de atender os alunos em suas peculiaridades. Mas essas adaptaçôes não são conduzidas sem tensão. Os alunos com necessidades educativas especiais, muitas vezes, solicitam as tarefas propostas aos demais alunos da turma. Alice e Rosana procuram analisar as situaçôes específicas para decidir em que momentos as diferenciaçôes são necessárias, procurando não velar as diferenças em nome de uma pretensa aprendizagem harmônica e homogênea.

Com relação aos alunos nomeados na condição de "normais", houve uma preocupação constante, por parte das professoras regentes, em também desafiá-los em termos de aprendizagens, bem como destes relacionarem-se cognitivamente com os demais alunos com necessidades educacionais especiais. O que fica evidente nesse movimento é que a diferença não deve ser subsumida e que os desafios serão diferentes de acordo com as diferenças que estáo em diálogo e em tensão no espaço da sala de aula.

Soubemos também de várias histórias familiares da turma, as quais sinalizaram diferenças em vários âmbitos. Destacamos aqui a postura do aluno G., considerado pelo seu histórico em situação de vulnerabilidade social, a qual foi se alterando durante as aulas. Inicialmente houve certa resistência em fazer as atividades, em expor seu rosto (estava usando capuz tapando os olhos), inclusive ameaçou em um determinado 
momento retirar-se da sala. Paulatinamente, foi atendendo ao chamado das professoras, integrando-se ao trabalho em grupo.

Interrompemos, aqui, este primeiro recorte de vidas e aprendizagens em cena, querendo, fundamentalmente, mostrar que, para compreender um pouco mais sobre os modos por meio dos quais aqueles alunos aprendiam/estão aprendendo, foi/é preciso estar perto deles e de suas professoras, confrontando esses "dados" com nossos estudos e discussóes.

Para tanto, retomamos a noção de experiência como uma bússola a nos orientar analiticamente quanto aos saberes que nos capturaram em tantas cenas e cenários experienciados. Mais uma vez, Bondía (2004, p. 160) nos possibilita uma reflexão ao nos instigar o pensamento com a seguinte ideia:

A experiência, a possibilidade de que algo nos passe ou nos aconteça ou nos toque, requer um gesto de interrupção, um gesto que é quase impossível nos tempos que correm: requer parar para pensar, para olhar, parar para escutar, pensar mais devagar, olhar mais devagar e escutar mais devagar, demorar-se nos detalhes, suspender a opinião, suspender o juízo, suspender a vontade, suspender o automatismo da ação.

Trata-se, entáo, de uma investigaçáo em que a experiência, ao nos interpelar para a construçáo de uma postura investigativa de interação e intervençáo mais atenta e sensível, oportunizou-nos a "criação de dados" e não apenas uma simples "coleta de dados" ao depararmo-nos com os cenários descritos.

\section{Efeitos do processo de intervenção compartilhada}

A atividade de observação cujo foco era investigar as aprendizagens de alunos do III Ciclo, dentro do projeto de Docência Compartilhada, ganhou outros contornos a partir da nossa inserção/imersão na turma C12. Instaurou-se um processo vigoroso de interlocuçáo com Alice e Rosana, fomentado pelas aulas compartilhadas e por conversas e reuniôes agendadas em que analisávamos as práticas pedagógicas ocorridas.

Gostaríamos de salientar que muitas das intervençôes compartilhadas se processavam logo após os momentos de observação das aulas, pois percebíamos que as professoras regentes tinham expectativas sobre os acontecimentos recentemente vivenciados e uma disposição em dialogar sobre os mesmos. Em uma das situaçôes de término dos períodos de aula, por exemplo, enveredamos para a sala dos professores e 
comentamos com Alice e Rosana sobre os processos de mudança decorrentes das três aulas das quais já havíamos participado: o planejamento envolvendo vários materiais; a manutenção de um conteúdo em pauta por mais tempo pela sua significação e contextualização, através de diferentes estratégias; a necessidade de investir mais nas inferências de leitura, na interpretação dos aportes (livros, imagens, mapas, vídeos) e nas relaçóes entre os mesmos.

A professora pesquisadora R. sugeriu, entáo, a continuidade do trabalho, envolvendo a relaçấo homem-natureza, com a abordagem dos povos indígenas, considerando a possibilidade de que os alunos pudessem identificar aspectos comuns entre esses povos e o que já haviam estudado sobre os povos habitantes da região da Mesopotâmia. Além disso, havia a intenção de Rosana em aproximar os estudos da História Antiga dos estudos dos processos colonizadores no Brasil.

Conforme já salientado, havia a necessidade de um constante retorno do observado às professoras Alice e Rosana, o que nos instigou a delinear uma ação metodológica: posteriormente às observações, ocupávamos um turno registrando os acontecimentos; após, discutíamos e enviávamos esses escritos às professoras, para que fizessem suas leituras e comentários. Em sequência, marcávamos um encontro (professoras-pesquisadoras e professoras regentes) para discutir essas impressóes, no intuito de repensar práticas e propor encaminhamentos de novas propostas de trabalho. O excerto de diário de campo (Quadro 1) ilustra um começo de reuniáo em que Rosana se manifesta sobre os registros das observaçôes.

\section{Quadro 1 - Excerto Diário de Campo}

A reunião iniciou às $14 \mathrm{~h} 30 \mathrm{~min}$, quando Alice e Rosana chegaram. O reencontro é caloroso, com abraços e conversa inicial informal.

Professora pesquisadora M.I.: "queremos ouvir os comentários de vocês sobre os escritos das observaçóes e pensar nos encaminhamentos".

Rosana [comenta sobre nossas observações, o texto-registro escrito que enviamos]: "meu Deus, como vocês conseguem lembrar de tantos detalhes!" E prossegue: "é porque vocês estavam lá dando aula com a gente, não estavam só lá atrás sentadas. Gostei muito de ler os registros! Náo sei nem o que escrever para completar, escreveram tudo táo bonitinho e perfeito."

Fonte: Autoras.

Não há como deixar de ressaltar o valor da escrita do diário de campo. Ao escrever, o pesquisador coloca-se, novamente, em diálogo com os acontecimentos vivos, produzindo pensamentos sobre o que ocorreu, aprendendo mais sobre seu próprio trabalho e sobre uma escrita cuidadosa envolvendo o outro. Segundo Zabalza (1994), escrever sobre a prática nos leva a aprender através da narração. Ao narrarmos a 
experiência recente temos a oportunidade de construí-la linguisticamente por meio de argumentos, ou seja, a narração é um mote para a reflexão. Para as professoras, a leitura dos escritos, do mesmo modo, funcionou como um dispositivo de reorganização do pensamento e das ações pedagógicas: suas práticas estavam lá nos registros, sob a moldura das palavras que foram escolhidas por nós, para descrever a vida e as atividades pulsando... Eis que assim estávamos produzindo, também, "dados" de pesquisa.

Prosseguindo com as intervençôes compartilhadas, os registros das aulas nos permitiram identificar, como já referido, a necessidade de investir nas relaçôes entre as diferentes leituras sobre um mesmo tema. Assim sendo, em uma situaçáo de leitura oral para a turma, tendo como obra escolhida o livro Rei Gilgamesh ${ }^{6}$ - recontado e ilustrado por Ludmila Zeman (1997) -, os alunos demonstraram pouca curiosidade durante a contação. Ocorreu-nos que, se a narrativa tivesse sido interativa, ou seja, dialogada, explicativa, interrogativa (envolvendo significado de palavras dentro do contexto, relaçôes possíveis com o cotidiano, incluindo fatos da mídia ou das informaçôes já trabalhadas em outros textos, vídeos sobre a Mesopotâmia), talvez os leitores-ouvintes pudessem ter ressignificado, de maneira mais compreensiva, a história. De acordo com a noçâo de leitura significativa proposta por Smith (1999, p.15), "o significado não é algo que o leitor ou o ouvinte recebe da linguagem, mas algo que é trazido para a linguagem". Essa é uma questão importante quando propomos uma atividade de leitura, ou seja, ativar os conhecimentos prévios dos leitores pode gerar um engajamento mais profícuo no exercício da compreensão. Fomos em frente...

No decorrer desta prática de leitura, houve uma intervenção de nossa parte, no intuito de instigar os alunos a observarem a beleza da moldura nas imagens contidas no livro (Alice também já havia destacado o belíssimo trabalho da ilustradora). Ao término da leitura, ela questionou os alunos sobre aspectos relevantes da história. Percebemos que, nesta tentativa de retomada do conteúdo do texto, as respostas náo surtiram os efeitos desejados. Ou seja, a compreensão e as relações com o que vinham aprendendo ainda não haviam sido suficientemente estabelecidas.

Na sequência, houve uma alteração compartilhada no roteiro da aula: Alice, habilmente, frente ao cenário interpretativo da narrativa, propôs a produção de desenhos que pudessem retomar/recontar elementos da história narrada, uma maneira de fazer a turma voltar ao texto, compreendendo-o, explicitando-o, em alguma medida, por meio de outra linguagem expressiva; assim inferimos em relação à decisão pedagógica tomada, com a qual concordamos inteiramente.

Nossa surpresa se deu com as produçóes elaboradas. Durante o processo, chamou-nos a atenção o modo como os alunos se apropriaram do item da moldura, recriando-as em seus desenhos, usando, para isso, um repertório já conhecido (próprio) 
de traços e cores. Eram essas produçóes, na verdade, versóes e olhares sobre o texto com o qual interagiram. Desse modo, confirmamos a ideia de que ler para recriar um texto, em outra linguagem, permite a articulação de sentidos variados, advindos de diferentes experiências de leitura que emergem na memória.

O fator diversidade de estratégias de aprendizagem, somado à manutenção de uma temática por mais tempo no planejamento compartilhado, levou-nos a ponderar sobre as diferentes e necessárias formas de ação pedagógica, pois, sob nossa concepção, os alunos aprendem lendo, escrevendo, observando, discutindo, desenhando e sempre que provocados a generalizar/relacionar. Os alunos aprendem, também, em diálogos fecundos com seus professores e com seus pares. Isso leva tempo? Que tempo, se considerarmos um grupo de sete alunos (além dos demais da turma) táo singular? Nossa experiência e a produção dos dados selecionados neste estudo sinalizam, mais uma vez, a relevância da qualidade das intervençóes: acolhida de curiosidades, escuta de dúvidas, explicaçôes ilustradas com exemplos do cotidiano, isto é, a prática do que Perrenoud (2000) chama de "pedagogia diferenciada". Nas palavras do autor,

Praticar uma pedagogia diferenciada é fazer com que, quando necessário, cada aluno seja recolocado ou reorientado para uma atividade fecunda para ele. [...] entrar em relaçáo, instaurar um diálogo sobre o saber e a aprendizagem. Um dispositivo de pedagogia diferenciada aumenta a probabilidade de que cada indivíduo ou cada grupo encontre, na hora certa, um interlocutor bastante disponível e competente para assumir a situação e reorientar seu trabalho[...]. O diálogo é o princípio da observação formativa, da expressão das representações do aprendiz, da identificação dos obstáculos com os quais se depara e dos erros que comete. Tendo o dispositivo criado condiçóes favoráveis a esse diálogo, a diferenciação depende do talento, da imaginação, da perspicácia e da disponibilidade dos professores. Depende, ainda mais, de sua capacidade de entrar em relação (PERRENOUD, 2000, p. 73, grifo nosso).

Até aqui trabalhamos com a ideia de intervenção compartilhada, focando a questão das aprendizagens de professoras, alunos e de professoras-pesquisadoras; os alunos, sendo instigados a ampliar conhecimentos de acordo com suas possibilidades; as professoras e as professoras-pesquisadoras pesquisando, selecionando materiais, retomando percursos para concretizar aprendizagens que superassem/superem "modelos tradicionais" de ensinar, avaliar, aprender, pesquisar...

Entretanto, há de se tocar ainda em um aspecto de extrema relevância nesse processo de acompanhamento pedagógico, isto é, a estratégia de intervenção 
compartilhada. Ele diz respeito à formação de professoras autoras não só de práticas pensadas, planejadas e implementadas por meio da DC, mas também autoras de escritas analíticas sobre essas práticas. É o educador Nóvoa (2003, p. 27, grifo nosso) quem nos faz refletir sobre as relaçóes entre a pesquisa e a necessidade de apropriação de saberes sobre si por meio da escrita-registro, quando destaca que:

A pesquisa passa sempre por uma prática de registro que ajuda à formalização de um saber específico, à sua partilha e ao reconhecimento social de um dado grupo profissional. Escrever é um dos modos mais eficazes de transformar a experiência em conhecimento. Por isso, é tão importante que os professores assumam uma palavra escrita.

Durante os encontros de discussão fomentamos a necessidade de as professoras regentes se apropriarem, ainda mais, desta experiência da palavra escrita, retomando registros e debruçando-se sobre eles para identificar um foco de escrita. E assim foi feito: Alice e Rosana decidiram dissertar sobre a vivência da Docência Compartilhada, abordando sua complexidade e sua potência. Escreveram um artigo, sob nossa orientação, e socializaram-no em um e-book organizado pelo nosso grupo de pesquisa (TRAVERSINI, 2013). Relembramos aqui Bondía (2004) ao nos dizer que é preciso uma abertura para a escuta, para o acolhimento de ideias; é necessária uma interrupção para pensar, para re-organizar açôes. Essa pré-disposição e suspensão podem se dar na prática docente de sala de aula, bem como através da escrita reflexiva conforme já mencionamos.

\section{A intervenção compartilhada e suas implicações na pesquisa: para concluir}

A partir das reflexôes e análises apresentadas no decorrer deste texto, constatamos que a presente pesquisa, pelos diferentes encaminhamentos adotados, pode ser compreendida como uma experiência metodológica de intervenção compartilhada. Tal compreensão se dá na medida em que esta foi capaz de envolver e desafiar as professoras regentes e as professoras-pesquisadoras, por meio da escritaregistro de cada acontecimento (observaçóes, reuniôes e conversas), que funcionou como propulsora de discussóes, análises e encaminhamentos de novas açốes pedagógicas. As professoras Alice e Rosana, ao lerem sobre suas práticas pedagógicas, dialogaram com as professoras-pesquisadoras, entre elas e consigo mesmas; reconheceram-se nas narrativas, sentiram-se instigadas e retomaram determinadas 
situaçôes com relativo distanciamento, o que provocou múltiplos posicionamentos, tomadas de decisóes e novos saberes sobre a docência.

Destacamos os registros escritos e as práticas de leitura, as conversas e reuniôes como um tempo e um espaço profícuo de trocas e produção de conhecimentos na construção da intervenção compartilhada. Esses momentos abriram possibilidades frente ao já estabelecido como regra, norma, tradicional e conhecido, cotidianamente, no ambiente escolar. Nesse sentido, Alice e Rosana transmutaram-se em protagonistas de práticas pedagógicas ressignificadas, bem como seus alunos assumiram posições de empoderamento com relação aos saberes apropriados. Foi uma experiência que modificou a todos que se deixaram tocar e afetar pelas circunstâncias do vivido compartilhado.

Identificamos, ainda, indícios de uma qualificação do projeto de Docência Compartilhada envolvendo as professoras Alice e Rosana, quando muitas das atividades passaram a ser planejadas conjuntamente, de forma mais sistemática e frequente, oportunizando momentos de trocas, questionamentos e sintonias. Também percebemos deslocamentos nas posiçóes dessas professoras em sala de aula (Pedagoga e professora de História), caracterizando um processo de hibridização de posiçôes e de tênues limites entre os territórios de saberes que cada uma habitava. Ou seja, as professoras regentes respondiam às necessidades dos alunos tanto nos conhecimentos específicos quanto na organização da turma. Borraram-se as fronteiras entre a pedagoga e a especialista.

Também cabe salientar que muitos "dados" obtidos em relação às aprendizagens das crianças e jovens com necessidades educativas especiais, bem como dos demais alunos da turma, demonstraram que havia um potencial, uma vontade de saber mais e uma disponibilidade por parte das professoras Alice e Rosana em preparar atividades diferenciadas para determinados alunos. Foi possível perceber que, em suas interlocuçóes e diálogos sobre as experiências de aprendizagem, as professoras regentes demonstravam conhecimentos sobre os avanços de cada um, dispondo de materiais específicos documentados. Observamos que, em certos momentos, as atividades diferenciadas estavam, de fato, acontecendo, com os diferentes grupos, no espaço da sala de aula.

Percebemos que esta questão da diferenciação é um ponto nevrálgico para as professoras regentes, considerando que alguns alunos com necessidades educativas especiais reivindicam as tarefas dadas aos demais da classe, as quais reforçariam a sua posição de aluno e de igualdade no grupo. Eis um dilema sobre o qual Alice e Rosana se interrogavam o tempo todo: como dar atenção à diversidade, quando os alunos com necessidades educativas especiais "desejam" uma certa homogeneidade e padronizaçáo 
para se sentirem "iguais"? Tal situação pareceu acompanhar as professoras regentes e as professoras-pesquisadoras como uma dos inúmeros dilemas e tensionamentos da DC e das práticas pedagógicas inclusivas.

As aprendizagens, tanto dos alunos com necessidades educativas especiais quanto dos demais da turma, não ocorreram apenas na dimensão da socialização, mas também no âmbito do cognitivo. Os trabalhos a que tivemos acesso (produçâo de textos sobre a Mesopotâmia, desenhos, maquetes e cartazes sobre os povos indígenas, planejamento e execuçáo de uma viagem às Missóes Jesuíticas, troca de cartas entre professoras-pesquisadoras e alunos narrando o que mais gostaram de aprender durante o ano letivo de 2011, diálogos e intervençôes orais dos alunos, índice-memória do projeto povos indígenas, preparação da Mostra - Museu Vivo - sobre o citado projeto) evidenciaram aquelas aprendizagens/conhecimentos.

Nesse rol de situaçóes acima elencadas, identificamos aprendizagens diferenciadas: os alunos com necessidades educativas especiais apresentam um tempo e um modo peculiar de apropriar-se dos conhecimentos, assim como os demais alunos sentem-se interpelados por esse modo singular de aprender e tornam-se parceiros que aprendem e ensinam ao mesmo tempo. Como nos lembra Certeau (1994, p. 38), “[...] o cotidiano se inventa com mil maneiras de caça não autorizada". E os alunos, com suas diferenças, inventaram formas de fomentar momentos de aprendizagens compartilhadas.

Neste estudo procurou-se, então, fazer um jogo de luzes e sombras para que ora as professoras regentes tivessem maior visibilidade, e ora os alunos com necessidades educativas especiais fossem o centro dos olhares, assim como os demais alunos também pudessem estar em evidência, sem deixar, igualmente, na penumbra a presença das professoras- pesquisadoras. Todos os sujeitos foram envolvidos, tanto como protagonistas quanto como coadjuvantes, alternando-se o foco dos olhares, para que os efeitos pudessem compor e tramar caleidoscopicamente esta investigação, de modo a perscrutar os desafios e dilemas da instigante experiência da intervenção compartilhada na sala de aula.

\section{Notas}

${ }^{1}$ Esta atividade de campo faz parte de um projeto de pesquisa mais amplo do referido grupo de pesquisa.

${ }^{2}$ Esses nomes são fictícios para preservar a identidade das professoras. A Pedagoga será chamada de Alice e a professora de História será chamada de Rosana. 
3 Conforme Prieto (2005, p. 102), “Quando na década de 90, a expressão 'necessidades educacionais especiais' passa a ser empregada, ela sugere a ampliaçáo da população que requer atendimento educacional especializado para além das deficiências, e não apenas os que se encontram nessa condição, já que, por exemplo, a superdotaçáo não pode ser assim caracterizada, tampouco os quadros de transtornos de desenvolvimento, tipo esquizofrenia, autismo e outros". Portanto, nesta investigação, tomamos a noção de necessidades educacionais especiais no intuito de ampliar o leque de sujeitos incluídos na escola, abrangendo crianças e jovens que se encontram em situação de vulnerabilidade social, entre outras. Também utilizaremos a denominação necessidades educativas especiais associada à noção referida.

${ }^{4}$ Durante o período de observaçóes, professoras do grupo de pesquisa, atuaram em sala de aula com Alice e Rosana, e posteriormente participaram das reuniōes de discussão sobre as práticas docentes.

${ }^{5}$ I., assim como vários alunos, trocavam bilhetes pessoais durante as aulas, muitos deles versando sobre namoros; o interessante é que essa "prática de escrita" não autorizada ocorre paralelamente à tarefa escolar, sem que eles deixem de concluir as atividades propostas.

${ }^{6}$ Narrativa do gênero lenda cujo enredo remete à região da Mesopotâmia, cidade de Uruk. A obra traz imagens esteticamente muito ricas, podendo ser exploradas sob diversos aspectos (ZEMAN, 1997).

\section{REFERÊNCIAS}

ABRAMOVAY, Miriam et al. Juventude, violência e vulnerabilidade social na América Latina: desafios para políticas públicas. Brasília: UNESCO, BID, 2002.

CERTEAU, Michel de. A invenção do cotidiano: artes de sazer. Petrópolis, RJ: Vozes, 1994. v. 1.

BONDÍA, Jorge Larrosa. Notas sobre a experiência e o saber da experiência. Revista brasileira de educação, Rio de Janeiro, n. 19, p. 20-28, jan./abr. 2002.

BONDÍA, Jorge Larrosa. Linguagem e educação depois de Babel. Belo Horizonte: Autêntica, 2004. 
GALLO, Sílvio. As contribuições de Foucault à educação. Revista Instituto Humanitas, São Leopoldo, RS, ano 6, n. 203, 6 nov. 2006. Entrevista concedida por e-mail à Revista Instituto Humanitas. Disponível em:

$<$ http://www.ihuonline.unisinos.br/index.php?option=com_content\&view=article\& $\mathrm{id}=555 \&$ secao $=203>$. Acesso em: 29 mar. 2012.

GALLO, Sílvio. Uma apresentação: diferenças e educaçáo; governamento e resistência. In: LOPES, Maura Corcini; HATTGE, Morgana Domênica (Org.). Inclusão escolar: conjuntos de práticas que governam. Belo Horizonte: Autêntica, 2009.

KENSKI, Vani. Novas tecnologias, o redimensionamento do espaço e do tempo e os impactos no trabalho docente. Revista Brasileira de Educação, São Paulo, n. 8, maio/ago. 1998.

MANGUEL, Albert. A biblioteca à noite. São Paulo: Companhia das letras, 2006.

NÓVOA, António. Os professores estão na mira de todos os discursos. São o alvo mais fácil de abater. Revista Pátio, Porto Alegre, ano 7, n. 27, ago./out. 2003. Entrevista concedida à Revista Pátio.

PERRENOUD, Philippe. Pedagogia diferenciada: das intençôes à ação. Porto Alegre: Artes Médicas, 2000.

PIETRO, Rosângela Gavioli. Inclusão escolar: algumas consideraçôes sobre o conceito e suas implicaçôes. In: MACHADO, Adriana Marcondes et al. Psicologia e direitos humanos: educação inclusiva, direitos humanos na escola. São Paulo: Casa do Psicólogo; Brasília, DF: Conselho Federal de Psicologia, 2005, p. 99-105.

SARMENTO, Manuel Jacinto. O estudo de caso etnográfico em educação. In: ZAGO, Nadir; CARVALHO, Marília Pinto de; VILELA, Rita Amélia Teixeira (Org.). Itinerários de pesquisa: perspectivas qualitativas em Sociologia da Educação. Rio de Janeiro: DP\&A, 2003. p. 137-179.

SMITH, Frank. Leitura Significativa. Porto Alegre: Artes Médicas, 1999.

TRAVERSINI, Clarice Salete et al. Currículo e inclusão na escola de ensino fundamental. Porto Alegre: EDIPUCRS, 2013. E-book.

ZABALZA, Miguel Ángel. Diários de aula. Porto: Editora Porto, 1994.

ZEMAN, Ludmila. O rei Gilgamesh. 2. ed. Porto Alegre: Projeto, 1997. 


\section{Shared intervention in an inclusive classroom: a methodological experience in History teaching}

Abstract

The present study sought to examine a methodological experience in teaching History, from the process of shared intervention in an inclusive classroom, developed in a Municipal School of Porto Alegre/RS, organized by Training Courses, in which the investigated first-year class of $3 \mathrm{rd}$ cycle joined the Shared Teaching Project. This project was designed contemplating the didactic-pedagogic planning and teaching in the classroom jointly by two teachers - a licensed teacher in History and a licensed one in Pedagogy. Among the significant developments of this study, we point out the shared intervention as a methodological experience for teaching History. As a consequence of this experience, an inventory with the records written by the teachersresearchers and the reading of the same by inservice teachers; discussion meetings about the writings and the referrals. It was noticed that from the shared intervention, as a methodological experience in teaching History, pupils with special educational needs had a time and a peculiar mode of take ownership of knowledge, as well as the other students felt challenged by this singular mode of learning. It was also verified that the inservice teachers became protagonists of resignified pedagogical practices, while the teachers-researchers have become apprentices
Intervención compartida en una clase inclusiva: una experiencia metodológica en la enseñanza de Historia

\section{Resumen}

Este estudio buscó analizar una experiencia metodológica en la enseńanza de Historia, a partir de un proceso de intervención compartida en una clase inclusiva, desarrollada en una Escuela Municipal de Porto Alegre/Rio Grande do Sul, Brasil, organizada por medio de Ciclos de Formación, donde la clase del $1^{\circ}$ ańo del $3^{\circ}$ ciclo investigado ha integrado el proyecto de Docencia Compartida. El proyecto ha sido diseñado de manera que pudiese contemplar la planificación didáctica y pedagógica y la docencia en clase mediante la participación de dos profesores, una profesora licenciada en Historia y otra en Pedagogía. Entre los avances significativos del estudio, se destaca la intervención compartida como una experiencia metodológica para la enseñanza de la Historia. De esta experiencia se llevó a cabo: un inventario con los registros escritos por las profesoras-investigadoras y la lectura de los mismos por las profesoras-regentes; las reuniones de discusión de los escritos y los desdoblamientos. Se observó que por medio de la intervención compartida, como una experiencia metodológica en la enseñanza de Historia, los estudiantes con necesidades educativas especiales han presentado un tiempo y un modo peculiar para apropiarse de los conocimientos, así como los demás estudiantes han sentido interpelados por este singular modo de aprendizaje. También se constató que las profesoras-regentes se han transformado en protagonistas de las prácticas pedagógicas ressignificadas, mientras que las 
of a investigative position called, in this context, shared intervention.

Keywords: Inclusion. Learning Process. Teaching of History. profesoras investigadoras se han convertido en aprendices de una postura investigativa denominadas en este contexto de intervención compartida.

Palabras claves: Inclusión. Enseñanza de la Historia.

\section{Roseli Inês Hickmann}

E-mail: roselihi@uol.com.br

\section{Maria Isabel Dalla Zen}

E-mail: beladzen@terra.com.br

\section{Maria Luísa Merino de Freitas Xavier E-mail:mlxavier@uol.com.br}

